\title{
Amsterdam house price ripple effects in The Netherlands
}

\author{
Alfred Larm Teye \\ OTB - Department of Research for the Built Environment, \\ Technical University of Delft, Delft, The Netherlands \\ Michel Knoppel \\ Department of Macro and International Economics, University of Amsterdam, \\ Amsterdam, The Netherlands \\ Jan de Haan \\ Corporate Services, IT and Methodology, Statistics Netherlands, The Hague, \\ The Netherlands and OTB - Department of Research for the Built Environment, \\ Technical University of Delft, Delft, The Netherlands, and \\ Marja G. Elsinga \\ Faculty of Architecture and the Built Environment, Technical University of Delft, \\ Delft, The Netherlands
}

\begin{abstract}
Purpose - This paper aims to examine the existence of the ripple effect from Amsterdam to the housing markets of other regions in The Netherlands. It identifies which regional housing markets are influenced by house price movements in Amsterdam.

Design/methodology/approach - The paper considers the ripple effect as a lead-lag effect and a longrun convergence between the Amsterdam and regional house prices. Using the real house prices for secondhand owner-occupied dwellings from 1995q1 to 2016q2, the paper adopts the Toda-Yamamoto Granger Causality approach to study the lead-lag effects. It uses the autoregressive distributed lags (ARDL)-Bounds cointegration techniques to examine the long-run convergence between the regional and the Amsterdam house prices. The paper controls for house price fundamentals to eliminate possible confounding effects of common shocks.

Findings - The cumulative evidence suggests that Amsterdam house prices have influence on (or ripple to) all the Dutch regions, except one. In particular, the Granger Causality test concludes that a lead-lag effect of house prices exists from Amsterdam to all the regions, apart from Zeeland. The cointegration test shows evidence of a long-convergence between Amsterdam house prices and six regions: Friesland, Groningen, Limburg, Overijssel, Utrecht and Zuid-Holland.
\end{abstract}

(C) Alfred Larm Teye, Michel Knoppel, Jan de Haan and Marja G. Elsinga. Published by Emerald Publishing Limited. This article is published under the Creative Commons Attribution (CC BY 4.0) licence. Anyone may reproduce, distribute, translate and create derivative works of this article (for both commercial and non-commercial purposes), subject to full attribution to the original publication and authors. The full terms of this licence may be seen at http://creativecommons.org/licences/by/4.0/ legalcode

JEL classification $-+\mathrm{C} 01,+\mathrm{C} 12,+\mathrm{C} 13,+\mathrm{C} 21,+\mathrm{R} 30,+\mathrm{R} 32$

The authors are very grateful for the useful comments received on earlier version of this paper presented during the 2016 AREAUA conference in Alicante, Spain. This research is supported by funding from Statistics The Netherlands (CBS).
Received 25 November 2016

Revised 4 April 2017

6 June 2017

16 June 2017

Accepted 17 June 2017
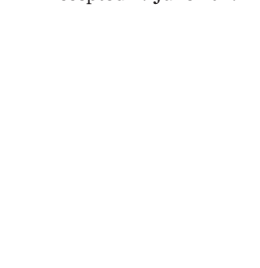
JERER
10,3

332

Research limitations/implications - The paper adopts an econometric approach to examine the Amsterdam ripple effect. More sophisticated economic models that consider the asymmetric properties of house prices and the patterns of interregional socio-economic activities into the modelling approach are recommended for further investigation.

Originality/value - This paper focuses on The Netherlands for which the ripple effect has not yet been researched to the authors' knowledge. Given the substantial wealth effects associated with house price changes that may shape economic activity through consumption, evidence for ripples may be helpful to policy makers for uncovering trends that have implications for the entire economy. Moreover, the analysis controls for common house price fundamentals which most previous papers ignored.

Keywords House prices, Amsterdam, Lead-lag effect, Ripple effect, Spatial causality

Paper type Research paper

\section{Introduction}

Real house prices in The Netherlands are reasonably correlated across regions. This may be mostly explained by the exposure to common factors, which are the main macroeconomic house price fundamentals. However, regional differences in real house price development exist, related to housing markets being local markets, subject to local influences. A first glance gives the impression that Amsterdam house prices are the first to move when compared to (some) other regions. This impression has stimulated our interest in the notion that Amsterdam house price development ripples to other Dutch regional housing markets. The ripple effect is conceptually a market phenomenon in which house price shocks in one region spread out their influence to house prices in other parts of the country (Meen, 1999; Nanda and Yeh, 2014; Balcilar et al., 2012). It manifests itself by way of house prices appreciating (down-turning) in one location, and subsequently appreciating (down-turning) in other regions (Giussani and Hadjimatheou, 1991).

There are several factors that may facilitate a house price ripple effect from Amsterdam to other regions in The Netherlands. First, the deterioration of housing affordability in Amsterdam, partly due to the wave of gentrification and urban regeneration, could shift the housing demand to the surrounding areas (Boterman et al., 2010). Second, recent internal migration patterns of certain groups of older adults in The Netherlands have been from urban to rural areas (De Jong et al., 2016). These migration patterns may explain why the housing demand and house prices in regions further away from Amsterdam may be stimulated (Meen, 1999). Third, house price spillovers from one region to another may be related to the general psychology and expectation of home-owners (Boelhouwer et al., 2004; Shiller, 1990). In an environment of low interest rates and higher demand for other regions, price changes in Amsterdam may induce house owners in the surrounding regions to similarly increase their asking prices beyond what one would rationally expect of the fundamentals (Case and Shiller, 1988; Abraham and Hendershott, 1994).

The existence of ripple effects is an important question for policymakers. Because a house is the largest asset for most households, house price changes have significant wealth effects, which to an extent also determine the degree of economic activity through consumption. The existence of a ripple effect thus suggests some predictability of house price trends in other regions, which may indicate regional wealth distribution and consumptions patterns that may affect the entire economy.

This paper examines the extent of a ripple effect existing from Amsterdam to other regional housing markets in The Netherlands over the period 1995 to 2016. From a more empirical perspective, the literature conforms to the definition that the ripple effect occurs if shocks to house prices in one region impact other regions, causing a lead-lag relationship or long-run convergence between the house prices (Giussani and Hadjimatheou, 1991; Meen, 
1999; Payne, 2012). In other words, it is necessary that the pairs of house prices exhibit a lead-lag effect and/or a co-integration relationship if a ripple effect exists. We test for the lead-lag effects via the application of the Toda-Yamamoto Granger Causality (GC) procedure. The cointegration relationships between the Amsterdam and regional house prices are estimated using the autoregressive distributed lags (ARDL)-Bounds approach. This method is consistent with the empirical applications by Giussani and Hadjimatheou (1991), MacDonald and Taylor (1993) and Holmes (2007), who studied the ripple effect for the UK.

This paper furthermore controls for house price fundamentals to eliminate possible confounding effects of common shocks which the previous papers ignored. In conclusion, the cumulative evidence suggests that Amsterdam house price developments may influence (or ripple to) all the regions in The Netherlands, except one. Particularly, the GC analysis suggests that house price lead-lag effects exist from Amsterdam to all regions, except Zeeland. Whereas the cointegration test finds evidence of a long-run impact existing from Amsterdam to Friesland, Groningen, Limburg, Overijssel, Utrecht and Zuid-Holland. Quarterly real average house price time series data for second-hand owner-occupied dwellings are used for the analyses.

The rest of the paper is structured as follows. Section 2 gives a brief overview of the empirical literature on ripple effects in housing markets. Section 3 presents an overview of house price developments in The Netherlands, indicating the differences that exist among the regions and between Amsterdam and the rest of the country. Section 4 discusses the empirical models and the estimation results. Section 5 concludes the paper.

\section{The empirical literature}

The ripple effect is a widely studied subject in the housing literature. An elaborate and a more recent review is provided in for example Nanda and Yeh (2014) and Gong et al. (2016). We only present a brief summary in this paper. Historically, housing researchers observed the ripple effect first in the UK. This was in the early 1990s when upswings in house prices from parts of the South-East, mostly London, were noticed subsequently in other regions of the UK (Giussani and Hadjimatheou, 1991; MacDonald and Taylor, 1993; Meen, 1999). Studies on the subject since then have been carried out in many other countries. Berg (2002) studied the ripple effect on the second-hand market for family houses in Sweden and found evidence for a ripple effect existing from Stockholm to other regions in Sweden.

In the USA, Canarella et al. (2012) for example studied the spatial interrelationships of house prices and concluded that ripple effect potentially exist from housing markets in the east and west coast metropolitan areas to the rest of the USA. Buyst and Helgers (2013), who analysed the case of Belgium, found that house price shocks are likely to "ripple" from Antwerp to the rest of the country. Gong et al. (2016) recently studied the case of China, and they found a unidirectional causal flow of house price shocks from the eastern-central region to the western parts in the Pan-Pearl River Delta of China.

In The Netherlands, the existence of a potential ripple effect is less certain, even though there is an upswing of house prices seemingly appearing first in Amsterdam and subsequently occurring in other parts of the country. Teye and Ahelegbey (2017) recently studied the house price diffusion process between the Dutch regional housing markets but did not specifically consider the Amsterdam effect. Pollakowski and Ray (1997), argued that the ripple effect may occur between regions that are economically related, although they need not necessarily border each other. Meen (1999) suggested that the ripple effects between regional house prices may be facilitated by economic activities, such as interregional migration, equity transfer and spatial arbitrage. 
JERER 10,3

\section{4}

Meen (1999) was also one of the first scholars to provide a general empirical method for studying the ripple effect in the housing context. His method is equivalent to testing the stationarity of the regional to national house price ratios. Using the traditional augmented Dickey-Fuller (ADF) test, however, Meen (1999) was not personally successful in confirming the ripple effect. In response, other scholars later used more advanced stationarity test procedures based on his empirical framework to study the ripple effect. For instance, the threshold and momentum threshold autoregressive test procedures were adopted by Cook (2003), while Holmes and Grimes (2008) combined unit root test and principal component analysis to examine the ripple effect for the UK. Canarella et al. (2012), also studied the house price ripple effect in the USA by combining the generalised least squares version of the ADF with non-linear unit root tests and other procedures that control for structure breaks. The Bayesian and panel seemingly unrelated regressions augmented Dickey-Fuller (SURADF) methods for testing unit roots have also been used by a section of the housing literature (Balcilar et al., 2012; Lee and Chien, 2011; Holmes, 2007).

Some researchers recently have advocated using dynamic spatial modelling approaches in which shocks from certain dominant regions are allowed to propagate to other locations and to echo back (Holly et al., 2010, 2011; Buyst and Helgers, 2013; Nanda and Yeh, 2014; Gong et al., 2016). Nevertheless, methods such as cross-correlations, GC, cointegration and impulse response analysis, are still commonly used for studying the ripple effect (Giussani and Hadjimatheou, 1991; MacDonald and Taylor, 1993; Holmes, 2007; Vansteenkiste and Hiebert, 2011; Gupta and Miller, 2012a, 2012b; Brady, 2014). The analysis with these methods are relatively simple to perform and this paper adopts similar approaches.

\section{Regional house price differences from data}

Data on average regional house prices for second-hand owner-occupied dwellings in The Netherlands are obtained from Statistics The Netherlands (CBS) for the analysis in this paper[1]. The data indicate significant differences between regional average prices of owneroccupied dwellings in The Netherlands. In the last quarter of 2014, for instance, real average house price ranges from an estimated e239,932 in Noord-Holland to about e155,810 in Groningen. These regional house price differences may partly be explained by variations in the demographic and economic structures of the regions.

Table I presents the summary statistics, and Figure 1 displays the details of regional real average house price developments in The Netherlands over the period 1995q1-2016q2[2]. The figure shows that real average house prices are higher in Utrecht, Noord-Holland (including Amsterdam), Noord-Brabant and Gelderland, while relatively lower in Groningen, Friesland and in Zeeland. There is also an apparent co-movement between the regional house prices that may be explained by the effects of common fundamentals.

Figure 2 exhibits a clearer picture of the differences in development of real average house prices between Amsterdam and the rest of The Netherlands. As in Table I, Figure 2 equally indicates that houses in Amsterdam are on average more expensive than elsewhere in The Netherlands, which may be because Amsterdam is the capital where demand is extremely high. The differences in the average house prices between Amsterdam and the rest of The Netherlands are not constant, however. These tend to widen during an upswing and narrow in a downturn. This may be because Amsterdam house prices grow faster than other regions during an upswing (Van Dijk et al., 2011).

The figure also clearly reveals that house prices in Amsterdam are potentially the first to move during an upswing or downturn in The Netherlands. Following the 2007-2008 Global Financial Crisis (GFC) especially, we can observe that house prices started to decline in Amsterdam in the last quarter of 2008 and a period of one quarter later (2009q1) before the 


\begin{tabular}{lccccc}
\hline Region & Minimum & Median & Mean & Maximum & Standard deviation \\
\hline AM & 11.76 & 12.48 & 12.41 & 12.70 & 0.24 \\
GR & 11.41 & 11.98 & 11.92 & 12.20 & 0.23 \\
FR & 11.41 & 12.04 & 11.98 & 12.26 & 0.24 \\
DR & 11.61 & 12.15 & 12.09 & 12.35 & 0.20 \\
OV & 11.61 & 12.19 & 12.12 & 12.35 & 0.20 \\
FL & 11.70 & 12.16 & 12.11 & 12.34 & 0.19 \\
GE & 11.78 & 12.39 & 12.30 & 12.54 & 0.20 \\
UT & 11.88 & 12.48 & 12.40 & 12.66 & 0.20 \\
ZH & 11.66 & 12.25 & 12.19 & 12.45 & 0.20 \\
ZL & 11.49 & 12.09 & 12.01 & 12.32 & 0.24 \\
NB & 11.78 & 12.38 & 12.31 & 12.57 & 0.21 \\
LI & 11.74 & 12.16 & 12.11 & 12.31 & 0.15 \\
$r$ & -1.22 & 2.00 & 1.91 & 5.15 & 1.48 \\
gdp & 13.16 & 13.46 & 13.43 & 13.57 & 0.11 \\
& & & & &
\end{tabular}

Notes: All values are in log except interest rates; $G R=$ Groningen; $F R=$ Friesland, $D R=$ Drenthe; $O V=$ Overijssel; $F L=$ Flevoland; $G E=$ Gelderland; $U T=$ Utrecht; $N H=$ Noord-Holland; $Z H=$ Zuid-Holland; $Z E=$ Zeeland; $N B=$ Noord-Brabant; $L I=$ Limburg; $r=$ Real interest rate

Amsterdam house price ripple effects

Table I.

Summary statistics for real average house prices and the control variables

decrease began in the rest of The Netherlands. As discussed in the previous section, observing house price cycles first in Amsterdam and later in other regions may be that house prices are merely more volatile in Amsterdam than in the other regions or possibly the decline of house prices later in the rest of The Netherlands is a direct response to the house price decreases in Amsterdam. The latter would indicate the ripple effect which this paper studies.

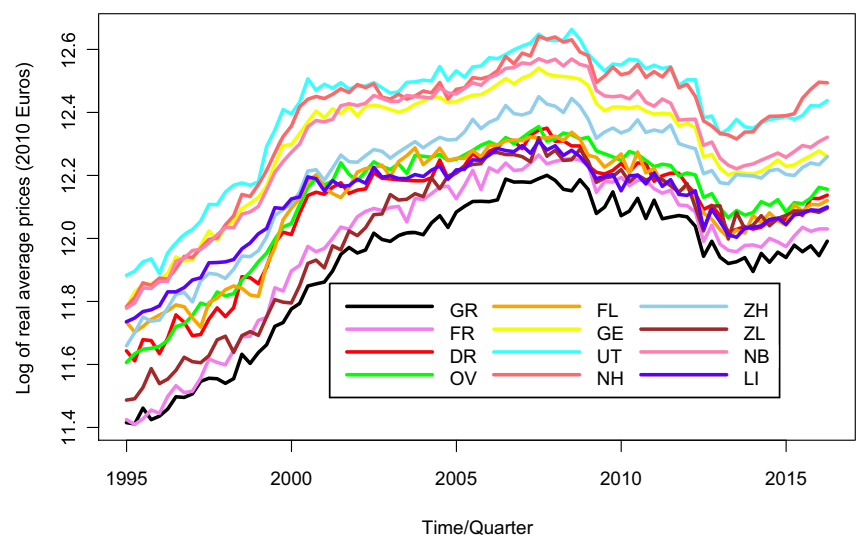

Notes: $G R=$ Groningen, $F R=$ Friesland, $D R=$ Drenthe, $O V=$ Overijssel, $F L=$ Flevoland, $G E=$ Gelderland, $U T=$ Utrecht, $N H=$ Noord-Holland (including Amsterdam), $Z H=$ Zuid-Holland, $Z E=$ Zeeland, $N B=$ Noord-Brabant, $L I=$ Limburg

Source: Statistics The Netherlands, OECD

Figure 1.

Regional real average house prices in The Netherlands (1996q12016q2) 


\section{JERER 10,3}

\section{6}

Figure 2.

Quarterly regional average prices of owner-occupied dwellings (1996q1-2016q2)

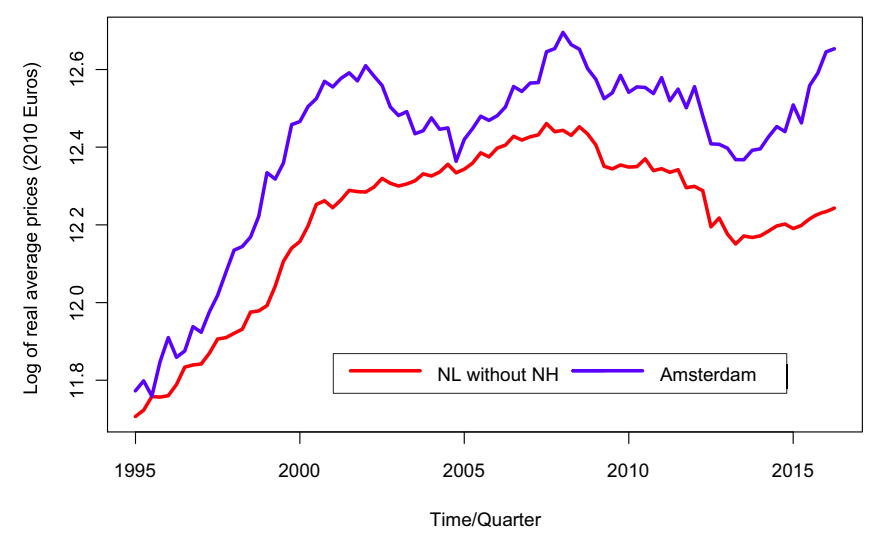

Notes: $\mathrm{NL}=$ The Netherlands, $\mathrm{NH}=$ Noord-Holland. The series for $\mathrm{NL}$ without $\mathrm{NH}$ are obtained as deflated weighted average of average house prices in all provinces of the Netherlands, leaving out $\mathrm{NH}$. We calculate the weights as the percentage of total houses sold in the Netherlands at the provinces' level

Source: Statistics the Netherlands, OECD

\section{Empirical methods and estimations}

Many papers that study ripple effects as a lead-lag relationship do so using simple crosscorrelation (Giussani and Hadjimatheou, 1991). The cross-correlation is most appropriate for capturing the relationship between two variables when one has a delayed effect on the other (Shumway and Stoffer, 2010). However, one drawback of simple cross-correlation is that it does not allow us to control for the cumulative lag effects of Amsterdam house prices. Moreover, it does not enable us to control for the house price fundamentals that may possibly confound the lead-lag effect. As these drawbacks may give misleading results, this paper applies GC and cointegration analyses. The GC provides a simple way to correct for the effects of common fundamentals and to account for the cumulative lag effects of Amsterdam house prices. The cointegration analysis provides a framework for determining the long-run convergence between the house prices.

\subsection{Granger causality analysis}

The underlying principle of GC is that the Amsterdam house prices should add significant information to the prediction of the regional house prices if there is a lead-lag effect (Granger, 1980, 1969). This paper uses the Toda and Yamamoto (1995) GC (TY-GC) test to study the lead-lag effect between the Amsterdam and regional house prices. The same method has been used by Gong et al. (2016) and Chen et al. (2011) who studied lead-lag relationships between regional house price indices.

There are advantages of using the Toda and Yamamoto (1995) approach for testing GC. In the original formulation, Granger (1969) provided a standard empirical technique for GC analysis that is applicable only for stationary time series. The TY-GC method, on the other hand, is suitable for the GC analysis with one or more time series being non-stationary. It also enables multivariate analysis, making it flexible to control for house price fundamentals 
that may possibly confound discernment of the lead-lag relationship between the house prices.

4.1.1 Toda-Yamamoto procedure. The TY-GC procedure involves testing linear restrictions in a lag-augmented vector autoregressive (VAR) model. More precisely, let $x_{t}$ and $y_{i t}$ be the house price series for Amsterdam and the region $i$, respectively, and suppose they follow the $\operatorname{VAR}(p)$ process with control variables(s) $z_{t}$ defined by:

$$
\begin{aligned}
{\left[\begin{array}{c}
y_{i t} \\
x_{t}
\end{array}\right]=} & {\left[\begin{array}{l}
\alpha_{0}+\gamma_{1} z_{t-1}+\cdots+\gamma_{q} z_{t-q} \\
\beta_{0}+\delta_{1} z_{t-1}+\cdots+\delta_{q} z_{t-q}
\end{array}\right]+\left[\begin{array}{ll}
\alpha_{11} & \beta_{11} \\
\alpha_{21} & \beta_{21}
\end{array}\right]\left[\begin{array}{c}
y_{i t-1} \\
x_{t-1}
\end{array}\right]+\cdots } \\
& +\left[\begin{array}{ll}
\alpha_{1 p} & \beta_{1 p} \\
\alpha_{2 p} & \beta_{2 p}
\end{array}\right]\left[\begin{array}{l}
y_{i t-p} \\
x_{t-p}
\end{array}\right]+\left[\begin{array}{l}
e_{1 t} \\
e_{2 t}
\end{array}\right]
\end{aligned}
$$

Amsterdam house price ripple effects

where $p, q \geq 1$. If $x_{t}$ and $y_{i t}$ were all stationary, the standard test that $x_{t}$ Granger causes $y_{i t}$ is equivalent to testing the null hypothesis:

$$
H_{0}: \beta_{11}=\cdots=\beta_{1 p}=0
$$

On the other hand, this test is statistically invalid and needs to be modified if at least one of the series is non-stationary. Toda and Yamamoto (1995) provided a simple modification when there are non-stationary time series. Their method augments the $\operatorname{VAR}(p)$ model with $k$ additional lags and then tests $H_{O}$ from the resulting $\operatorname{VAR}(p+k)$ model, neglecting the extra $k$ lags which have zero coefficients in principle. The lag augmentation is used to preserve the asymptotic distribution of the Wald test-statistics on addition of the non-stationary series. The value for $k$ is determined as the maximal order of integration between the time series.

4.1.2 Results. The implementation of the TY-GC test requires pre-testing the integration order of the house price series. We use the log real average house prices, which are confirmed as I(1) series by the standard ADF test in Table II. This also means that $k$ must be set equal to one in each of the region specific VAR model.

Thus, the TY-GC test is performed with a VAR $(p+1)$ model to estimate the lead-lag effect between the regional and house Amsterdam prices. We include the two most important Dutch house price fundamentals for $z_{t}$ : real GDP $\left(g d p_{t}\right)$ and real interest rates $\left(\gamma_{t}\right)$ (De Vries, 2010; Toussaint and Elsinga, 2007; Boelhouwer, 2002, for thorough discussions of the determinants of Dutch house prices). We use the national real GDP, as this data is unavailable to us at the regional level. In The Netherlands, the credit market is uniform across all the regions and most mortgage contracts are fixed for five years or longer periods (De Haan and Sterken, 2005). Thus, the long-term real interest rates are used for the estimations[3].The lag order $p$ is estimated from a VAR model for the four variables $y_{i t}, x_{t}$, $g d p_{t}$ and $r_{t}$ separately for each region $i$ using AIC. The statistically insignificant lags for $g d p_{t}$ and $r_{t}$ from the estimated VAR model are dropped to obtain the lag $q$. For each region $i$, we find $q=1$.

To proceed with the $\mathrm{GC}$ analysis, it is empirically important that the residuals from the model (1) are serially uncorrelated. If the residuals exhibit serial correlation, $p$ is increased by one until there is at least first-order serial independence at the 5 per cent statistical significance level. The Breusch-Godfrey LM serial correlation test statistics are marked $\chi^{2}{ }_{s C}(1)$ in Table III(a). The null hypothesis for the GC test is stated specifically as:

HO. Amsterdam house prices do not Granger cause house prices in the specified region. 


\begin{tabular}{|c|c|c|c|c|c|}
\hline $\begin{array}{l}\text { JERER } \\
10,3\end{array}$ & \multicolumn{3}{|c|}{ Levels } & \multicolumn{2}{|c|}{ First-difference } \\
\hline \multirow{5}{*}{338} & $\mathrm{AM}$ & $0.88(0)$ & 0.90 & $-4.55(1)$ & $0.00^{* * * *}$ \\
\hline & GR & $0.15(5)$ & 0.72 & $-2.13(4)$ & $0.03^{* *}$ \\
\hline & FR & $0.15(4)$ & 0.73 & $-2.77(3)$ & $0.01 * * *$ \\
\hline & DR & $0.64(0)$ & 0.85 & $-2.86(3)$ & $0.00^{* * * *}$ \\
\hline & OV & $0.71(0)$ & 0.87 & $-8.55(0)$ & $0.00 * * *$ \\
\hline \multirow{10}{*}{$\begin{array}{l}\text { Table II. } \\
\text { ADF test for (log) } \\
\text { average real house } \\
\text { prices and control } \\
\text { variables }\end{array}$} & FL & $0.23(2)$ & 0.75 & $-5.29(1)$ & $0.00^{* * * *}$ \\
\hline & $\mathrm{GE}$ & $0.12(0)$ & 0.72 & $-7.78(0)$ & $0.00^{* * * *}$ \\
\hline & UT & $0.37(0)$ & 0.79 & $-9.81(0)$ & $0.00 * * *$ \\
\hline & $\mathrm{ZH}$ & $0.31(4)$ & 0.77 & $-2.88(3)$ & $0.00 * * *$ \\
\hline & ZL & $0.28(5)$ & 0.76 & $-1.87(5)$ & $0.06^{*}$ \\
\hline & NB & $-0.12(4)$ & 0.64 & $-2.69(3)$ & $0.01^{* * * *}$ \\
\hline & LI & -0.09 (3) & 0.65 & $-3.87(2)$ & $0.00^{* * *}$ \\
\hline & $r$ & $-1.57(0)$ & 0.11 & $-6.86(0)$ & $0.00^{* * *}$ \\
\hline & gdp & 2.09 (1) & 0.99 & $-4.58(0)$ & $0.00 * * *$ \\
\hline & \multicolumn{5}{|c|}{$\begin{array}{l}\text { Notes: Real interest rate is denoted by } r \text {. ADF test regression is estimated separately for each time series } \\
\text { without deterministic trend and intercept. The optimal lag, indicated in parenthesis, is estimated using BIC; } \\
*, * * \text { and } * * * \text { denote statistical significance at the } 10,5 \text { and } 1 \% \text {, respectively }\end{array}$} \\
\hline
\end{tabular}

A rejection of this null hypothesis implies there is GC, suggesting a lead-lag effect in which Amsterdam house price movements are associated with subsequent house price developments in the respective regions. The results of the test are summarised in Table III(a).

The table indicates the hypothesis that no GC exists could be rejected at the 5 per cent statistical significance level for all the regions, except in the case of Drenthe and Zeeland. Nevertheless, GC could be weakly confirmed for Drenthe at the 6 per cent statistical level.

\subsection{Cointegration and long-run relationships}

The preceding subsection analysed the lead-lag effects between the Amsterdam and regional house prices using the TY-GC approach. This subsection studies the cointegration relationships between them. A cointegration relationship determines the long-run convergence, which suggests a ripple effect between the Amsterdam and regional house prices (Meen, 1999; Payne, 2012).

We use the ARDL-Bounds cointegration procedure of Pesaran et al. (2001) to test the existence of cointegration relationships in this paper. This approach allows us to control for the house price fundamentals, and it is generally flexible enough to enable inclusion of both stationary and non-stationary time series in the test procedure. The ARDL-Bounds approach to cointegration is the most appropriate among existing methods for the shorter study period in this paper (Narayan, 2005, for a discussion on the choice of cointegration techniques). It was similarly adopted by Payne (2012) who studied the long-run convergence and ripple effects among regional housing prices in the USA.

4.2.1 Autoregressive distributed lags cointegration procedure. The Pesaran et al. (2001) ARDL-Bounds cointegration test between $x_{t}$ and $y_{i t}$, controlling for the house price fundamentals is performed in several steps. Most importantly, it needs to be ensured that all the time series are not integrated beyond the first order. We can then formulate an unrestricted error correction (UEC) model which forms the basis for the test.

The model in this paper is of the form: 


\begin{tabular}{|c|c|c|c|c|}
\hline Region & Test-statistic & $\operatorname{Lag}(p)$ & $P$-value & $X_{S C}^{2}(1)$ \\
\hline \multicolumn{5}{|c|}{ (a) Toda-Yamamoto GC test } \\
\hline GR & 3.20 & 3 & $0.03^{* *}$ & $0.59(0.44)$ \\
\hline FR & 5.03 & 3 & $0.00 * * *$ & $2.98(0.08)^{*}$ \\
\hline $\mathrm{DR}$ & 2.19 & 6 & $0.06^{*}$ & $0.86(0.35)$ \\
\hline OV & 6.67 & 3 & $0.00 * * *$ & $0.02(0.87)$ \\
\hline FL & 3.27 & 5 & $0.01^{* * *}$ & $0.04(0.85)$ \\
\hline GE & 4.87 & 2 & $0.01^{* * * *}$ & $3.37(0.07)^{*}$ \\
\hline UT & 6.85 & 2 & $0.00^{* * *}$ & $1.81(0.18)$ \\
\hline $\mathrm{ZH}$ & 5.40 & 3 & $0.00^{* * *}$ & $0.57(0.45)$ \\
\hline ZL & 1.22 & 3 & 0.31 & $2.56(0.46)$ \\
\hline NB & 8.25 & 2 & $0.00^{* * *}$ & $1.11(0.29)$ \\
\hline LI & 3.61 & 3 & $0.02^{* *}$ & $0.00(0.99)$ \\
\hline Independent variable & Estimate & Std. Error & t-value & $\mathrm{P}$-value \\
\hline \multicolumn{5}{|c|}{ (b) Regression results when Flevoland is the dependent region $\left(y_{t}^{i}, \mathrm{i}=U T\right)$} \\
\hline Const. & 0.40 & 0.73 & 0.54 & 0.58 \\
\hline$y_{t-1}^{i}$ & 0.69 & 0.12 & 5.81 & $0.00 * * *$ \\
\hline$y_{t-2}^{i}$ & 0.16 & 0.11 & 1.41 & 0.16 \\
\hline$x_{t-1}$ & 0.18 & 0.08 & 2.18 & $0.03 * *$ \\
\hline$x_{t-2}$ & 0.10 & 0.10 & 0.98 & 0.33 \\
\hline$x_{t-3}$ & -0.16 & 0.09 & -1.87 & $0.07 *$ \\
\hline$g d p_{t-1}$ & 0.00 & 0.08 & 0.01 & 0.99 \\
\hline$r_{t-1}$ & 0.01 & 0.00 & 1.79 & $0.08^{*}$ \\
\hline
\end{tabular}

Notes: In (a), test is performed separately for each region using VAR(p +1$)$ model with constant term and control variables (real GDP and real interest rates). The lag $p$ is estimated using AIC. The reported teststatistics are the Wald statistics. $\chi_{s c}^{2}(1)$ is the first-order LM test-statistic ( $p$-value in parenthesis) which indicates the independence of the residuals from the augmented regression equation for each region; In (b), the Amsterdam log real average house prices is represented by the series $x_{t}$. Residual standard error $=0.03$, multiple $R$-squared $=0.97$ and the adjusted $R$-squared $=0.96$. The Toda-Yamamoto procedure tests for the joint significance of the first $p$ lags of $x_{t}$ in the regression. Statistical significance is denoted by; * ** and *** at the 10,5 and $1 \%$ levels, respectively

Amsterdam house price ripple effects

339

Table III.

Toda-Yamamoto GC test-statistics and regression exhibit

$$
\begin{aligned}
\Delta y_{i t}= & \alpha+\sum_{j=1}^{p} \gamma_{j} \Delta y_{i t-j}+\sum_{j=1}^{q} \alpha_{j} \Delta x_{t-j}+\sum_{j=1}^{l} \beta_{j} \Delta g d p_{t-j}+\sum_{j=1}^{s} \eta_{j} \Delta \gamma_{t-j} \\
& +\pi_{1} y_{i t-1}+\pi_{1} x_{t-1}+\pi_{3} g d p_{t-1}+\pi_{3} r_{t-1}+\epsilon_{t}
\end{aligned}
$$

The lags $p, q, l$ and $s$ may be optimally chosen using an information criterion. Moreover, they must be adjusted if necessary to ensure that the error sequence $\epsilon_{t}$ is serially independent and that the autoregressive structure of the Model (3) is dynamically stable.

For region $i$, the hypothesis that no cointegration exists is performed separately using the Wald statistic and the F-critical bounds provided by Pesaran et al. (2001). The null hypothesis is equivalent to the coefficients of the lags; $x_{t}-1, y_{i t}-1, g d p_{t}-1$ and $r_{t}-1$, in equation (3) being statistically insignificant. This may be expressed explicitly as:

$$
H_{0}: \pi_{1}=\pi_{2}=\pi_{3}=\pi_{4}=0
$$

4.2.2 Results. The ARDL-Bounds cointegration method requires that the house price series and the control variables are not integrated beyond the first order. The log of the variables which were established as I(1) series in the previous subsection (Table II) are also used here. 


\section{JERER 10,3}

340

The lags $p, q, l$ and $s$ are estimated following several steps similar to Giles (2013). To begin, a $\operatorname{VAR}\left(p_{\text {min }}\right)$ model is estimated for the four variables: $\Delta y_{i t}, \Delta x_{t}, \Delta g d p_{t}$ and $\Delta r_{t}$, separately for each region $i$, with the lagged terms $y_{i t}-1, x_{t}-1, g d p_{t}-1$ and $r_{t}-1$ specified as exogenous variables. The AIC is then used to select the $p_{\text {min }}$. In most cases, we find that the lags for $\Delta g d p_{t}$ and $\Delta r_{t}$ are not statistically significant beyond the first order. Thus, $l$ and $s$ are set equal to one in the UEC. Next, we estimate the UEC model over the grid $\left[1, p_{\min }\right] \times[1$, $\left.p_{\text {min }}\right]$ and select the optimal $p$ and $q$ using the AIC. When necessary, the resulting values are further increased by one until the residuals are serially independent.

Furthermore, the characteristic equation of the autoregressive part of the UEC model is assessed for dynamic stability. The details of the diagnostic statistics are presented in Table IV and Figure 3. The models are generally well-specified and stable, with the inverse roots of the characteristics equation all inside the unit circle (Figure 3). Table IV summarises the results of the bound cointegration test. At the 5 per cent level of statistical significance, the results suggest that cointegration exists between Amsterdam and only five regions in

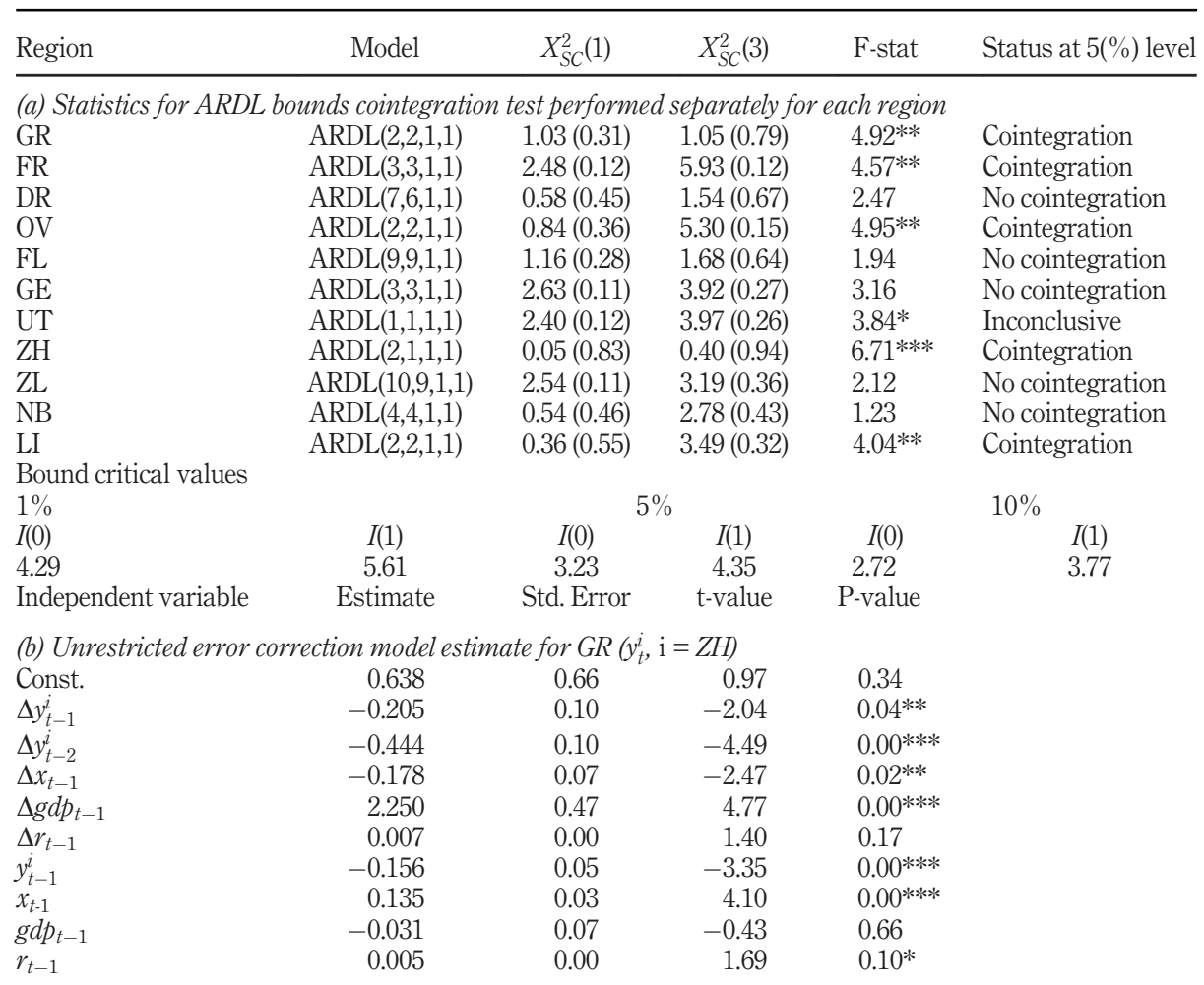

Table IV.

ARDL cointegration test-statistics and exhibit of the unrestricted error correction model
Notes: In (a), the UEC model is estimated with a constant for all regions. The lag order is selected with AIC and further adjustment when necessarily to correct for serial correlation and dynamic stability of autoregressive structure of the UEC model. $\chi^{2} s c(m)$ is the $m$-order LM residual serial correlation test of the estimated ARDL model. The critical values are taken from Table CI(iii) and and CII(iii) of Pesaran et al. (2001), with $k=3$; For the regression estimates in (b), the residual standard error $=0.02$, multiple $R$-squared $=0.46$ and the adjusted $R$-squared $=0.39$. Statistical significance is denoted by; $*, * *$ and $* * *$ at the 10,5 and $1 \%$ levels, respectively 


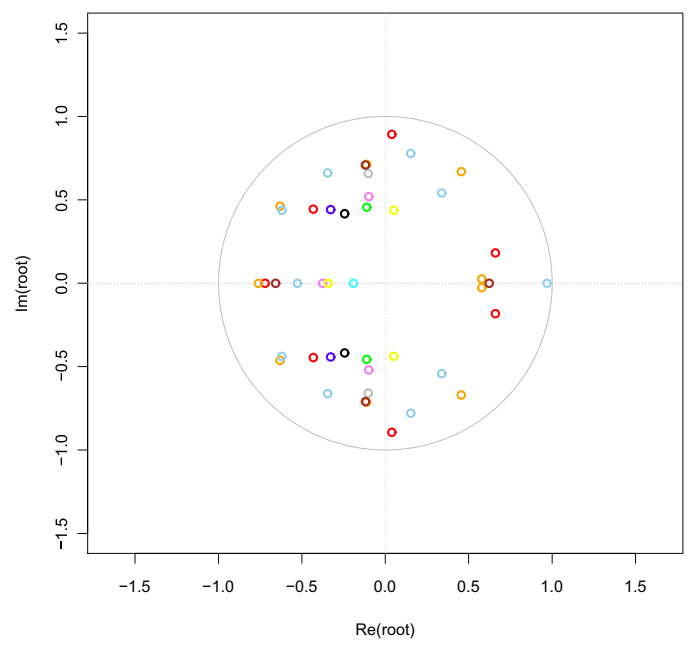

Amsterdam house price ripple effects

Notes: The inverse roots for the regions are coloured as: Black $=$ Groningen, Violet $=$ Friesland, Red $=$ Drenthe, Green $=$ Overijssel, Orange $=$ Flevoland, Yellow $=$ Gelderland, Cyan $=$ Utrecht, Gray $=$ Zuid-Holland, Sky-blue $=$ Zeeland, Brown $=$ Noord-Brabant, Blue $=$ Limburg

Figure 3. Inverse roots for $\mathrm{AR}$ characteristics equations

The Netherlands: Groningen, Friesland, Overijssel, Limburg and Zuid-Holland. Moreover, cointegration in the case of Utrecht could be confirm weakly at the 10 per cent statistical level, while no evidence exist to conclude on cointegration for the rest of the regions.

The specific long-run cointegration equation for these regions are presented in Table V. The coefficients on Amsterdam house prices are statistically significant and carry the expected positive sign in the long-run equation. In particular, a percentage increase in Amsterdam house prices is estimated to correspond respectively to $0.41,0.62,0.68,0.63,0.53$ and 0.73 per cent increase in houses prices of the six regions in the long run.

\begin{tabular}{lcccccr}
\hline Region & Constant & Amsterdam & GDP & $r$ & Adj. $R^{2}$ & RSE \\
\hline GR & $-13.51(1.88)^{* * * *}$ & $0.41(0.07)^{* * * *}$ & $1.50(0.19)^{* * * *}$ & $0.05(0.01)^{* * * *}$ & 0.88 & 0.08 \\
FR & $-11.87(1.87)^{* * * *}$ & $0.62(0.07)^{* * * *}$ & $1.20(0.19)^{* * *}$ & $0.05(0.01)^{* * * *}$ & 0.90 & 0.08 \\
OV & $-4.30(1.57)^{* * * *}$ & $0.68(0.06)^{* * * *}$ & $0.59(0.16)^{* * *}$ & $0.03(0.01)^{* * * *}$ & 0.89 & 0.07 \\
UT & $-3.99(1.34)^{* * * *}$ & $0.73(0.05)^{* * * *}$ & $0.54(0.13)^{* * *}$ & $0.04(0.01)^{* * * *}$ & 0.92 & 0.06 \\
ZH & $-7.59(1.46)^{* * * *}$ & $0.53(0.06)^{* * *}$ & $0.98(0.15)^{* * *}$ & $0.04(0.01)^{* * * *}$ & 0.90 & 0.06 \\
LI & $2.60(1.21)^{* *}$ & $0.63(0.05)^{* * *}$ & $0.12(0.12)$ & $0.03(0.01)^{* * *}$ & 0.88 & 0.05
\end{tabular}

Notes: Standard errors are reported in parenthesis. RSE is the residual standard error for the regression; *, $* *$ and $* * *$ denote statistical significance at the 10,5 and $1 \%$, respectively

Table V. Estimates of long-run relationships for cointegrating regions 


\section{JERER 10,3}

Table VI.

Conclusions from granger causality and cointegration test results at the $5 \%$ statistical significance level

\section{Discussions and concluding remarks}

The extent of house price spillover from Amsterdam to other regions in The Netherlands, the so-called ripple effect, has been examined for the period 1995q1-2016q2 in this paper. To determine the existence of spillovers, we corrected for the macroeconomic house price fundamentals; real GDP and real interest rates. The ripple effect is studied as a lead-lag relationship and long-run convergence between the house prices, for which we respectively applied GC and cointegration analyses.

Using real house price data series for second-hand owner-occupied dwellings, the results summarised in Table VI, can be divided into four categories. The first category contains one region for which there is no evidence of cointegration nor GC from Amsterdam (Zeeland). The second category constitutes four regions for which there is only GC from Amsterdam but no cointegration (Drenthe, Flevoland, Gelderland and NoordBrabant). The third category shows the regions for which there is evidence of both cointegration and GC from Amsterdam (Friesland, Groningen, Limburg, Overissel, Utrecht and Zuid-Holland). The fourth category exhibits evidence of GC from Amsterdam (includes all regions except Zeeland).

In conclusion therefore, the cumulative evidence suggests that Amsterdam house prices have some level of influence on (or ripple to) all the regions in The Netherlands, except Zeeland. The cointegration test which finds a long-run convergence between Amsterdam and Zuid-Holland or Utrecht is expected due to the close proximity. However, the cointegration in the case of the four regions (Friesland, Groningen, Limburg and Overijssel), is particularly interesting. This is because these regions are much distant from Amsterdam and also among the highly affordable regions with the lowest average house prices especially after 2005 (Figure 1).

Further research could shed more light on the economic mechanisms underlying these long-run convergence and ripple effects. Meen (1999) suggests that inter-regional migration may facilitate ripple effects between regional housing markets. One direction for further investigation might be to consider the extent to which housing affordability motivates house movers and internal-migrants from Amsterdam. The high affordability may be a pull-factor for certain class of households and individuals migrating from Amsterdam, which subsequently could affect house prices significantly. As neither GC nor cointegration is established between Amsterdam and Zeeland, which is also among the cheapest, this could mean that Zeeland is not a preferred destination for movers from Amsterdam. Yet, we leave

\begin{tabular}{llccc}
\hline Regions & GC & Cointegration & GC minus cointegration & No GC nor cointegration \\
\hline DR & $\mathrm{X}^{\dagger}$ & & $\mathrm{X}$ & \\
FL & $\mathrm{X}$ & & $\mathrm{X}$ & \\
FR & $\mathrm{X}$ & $\mathrm{X}$ & $\mathrm{X}$ & \\
GE & $\mathrm{X}$ & & & \\
GR & $\mathrm{X}$ & $\mathrm{X}$ & $\mathrm{X}$ & \\
LI & $\mathrm{X}$ & $\mathrm{X}$ & & \\
NB & $\mathrm{X}$ & $\mathrm{X}$ & $\mathrm{X}$ \\
OV & $\mathrm{X}$ & $\mathrm{X}$ & & \\
UT & $\mathrm{X}$ & $\mathrm{X}$ & & \\
ZH & $\mathrm{X}$ & $\mathrm{X}$ & & \\
ZL & & & & \\
\end{tabular}

Note: The applicable regions are marked X. † denotes GC or cointegration is only confirmed weakly at statistical level between 5 and $10 \%$ 
the confirmation of these suggestions to future research regarding the underlying explanations for the ripple effects.

It might also be useful to consider other approaches for studying the long-run convergence and ripple effect between Amsterdam and the regional house prices in a future research. Cook $(2003,2006)$, for instance, opined that the asymmetric properties of house prices may obscure how they interrelate spatially. This asymmetric property may also be considered for further investigation, in which a distinction is made between the nature of the house price ripple effect from Amsterdam to the other regions during upswings and downturns. Furthermore, an economic model that controls for the interregional socioeconomic activities may be adopted to explicitly trace their role in the house price spillover effect.

\section{Notes}

1. Dutch provinces are equated to regions in this paper.

2. House prices are not quality adjusted. Real average house prices are in 2010 Euros and are obtain by deflating the nominal values with consumer price index (CPI) obtained from the OECD.

3. This paper uses long-term real interest rates and real GDP from the OECD. The long-term real interest rates are obtained as nominal values minus inflation.

\section{References}

Abraham, J.M. and Hendershott, P.H. (1994), "Bubbles in metropolitan housing markets", Technical Report, National Bureau of Economic Research.

Balcilar, M., Beyene, A., Gupta, R. and Seleteng, M. (2012), "Ripple effects in South African house prices”, Urban Studies, Vol. 50 No. 5, pp. 876-894.

Berg, L. (2002), "Prices on the second-hand market for Swedish family houses: correlation, causation and determinants", European Journal of Housing Policy, Vol. 2 No. 1, pp. 1-24.

Boelhouwer, P.J. (2002), "Capital accumulation via homeownership: the case of the Netherlands", European Journal of Housing Policy, Vol. 2 No. 2, pp. 167-181.

Boelhouwer, P., Haffner, M., Neuteboom, P. and Vries, P. (2004), "House prices and income tax in the Netherlands: an international perspective”, Housing Studies, Vol. 19 No. 3, pp. 415-432.

Boterman, W.R., Karsten, L. and Musterd, S. (2010), "Gentrifiers settling down? Patterns and trends of residential location of middle-class families in Amsterdam", Housing Studies, Vol. 25 No. 5, pp. 693-714.

Brady, R.R. (2014), “The spatial diffusion of regional housing prices across US states”, Regional Science and Urban Economics, Vol. 46 No. 3, pp. 150-166.

Buyst, E. and Helgers R. (2013), "The ripple effect and the linguistic border in Belgium: a country divided?".

Canarella, G., Miller, S. and Pollard, S. (2012), "Unit roots and structural change an application to US house price indices", Urban Studies, Vol. 49 No. 4, pp. 757-776.

Case, K.E. and Shiller, R.J. (1988), "The behavior of home buyers in boom and post-boom markets", Technical Report, National Bureau of Economic Research Cambridge, MA.

Chen, P.F., Chien, M.S. and Lee, C.C. (2011), "Dynamic modeling of regional house price diffusion in Taiwan”, Journal of Housing Economics, Vol. 20 No. 4, pp. 315-332.

Cook, S. (2003), "The convergence of regional house prices in the UK", Urban Studies, Vol. 40 No. 11, pp. 2285-2294. 
JERER
10,3

344

Cook, S. (2006), "A disaggregated analysis of asymmetrical behaviour in the UK housing market", Urban Studies, Vol. 43 No. 11, pp. 2067-2074.

De Haan, L. and Sterken, E. (2005), “Asymmetric price adjustment in the Dutch mortgage market”, Technical Report, Research Department, Netherlands Central Bank.

De Jong, P.A., Brouwer, A.E. and McCann, P. (2016), "Moving up and down the urban hierarchy: agearticulated interregional migration flows in the Netherlands", The Annals of Regional Science, Vol. 57 No. 1, pp. 1-20.

De Vries, P. (2010), Measuring and Explaining House Price Developments, IOS Press, Vol. 36.

Giles, D.E. (2013), “Autoregressive distributed lag models - part ii - bounds tests”, Econometrics Beat, available at: http://davegiles.blogspot.com/2013/06/ardl-models-part-ii-bounds-tests.html

Giussani, B. and Hadjimatheou, G. (1991), "Modeling regional house prices in the United Kingdom", Papers in Regional Science, Vol. 70 No. 2, pp. 201-219.

Gong, Y., Hu, J. and Boelhouwer, P.J. (2016), "Spatial interrelations of Chinese housing markets: spatial causality, convergence and diffusion”, Regional Science and Urban Economics, Vol. 59 No. 4, pp. 103-117.

Granger, C.W. (1980), "Testing for causality: a personal viewpoint", Journal of Economic Dynamics and Control, Vol. 2, pp. 329-352.

Granger, C.W.J. (1969), "Investigating causal relations by econometric models and cross-spectral methods", Econometrica, Vol. 37 No. 3, pp. 424-438.

Gupta, R. and Miller, S.M. (2012a), "Ripple effects" and forecasting home prices in Los Angeles, Las Vegas and phoenix", The Annals of Regional Science, Vol. 48 No. 3, pp. 763-782.

Gupta, R. and Miller, S.M. (2012b), "The time-series properties of house prices: a case study of the Southern California market", The Journal of Real Estate Finance and Economics, Vol. 44 No. 3, pp. 339-361.

Holly, S., Pesaran, M.H. and Yamagata, T. (2010), “A spatio-temporal model of house prices in the USA”, Journal of Econometrics, Vol. 158 No. 1, pp. 160-173.

Holly, S., Pesaran, M.H. and Yamagata, T. (2011), "The spatial and temporal diffusion of house prices in the UK”, Journal of Urban Economics, Vol. 69 No. 1, pp. 2-23.

Holmes, M.J. (2007), "How convergent are regional house prices in the united kingdom? Some new evidence from panel data unit root testing", Journal of Economic and Social Research, Vol. 9 No. 1, pp. 1-17.

Holmes, M.J. and Grimes, A. (2008), "Is there long-run convergence among regional house prices in the UK?”, Urban Studies, Vol. 45 No. 8, pp. 1531-1544.

Lee, C.C. and Chien, M.S. (2011), "Empirical modelling of regional house prices and the ripple effect", Urban Studies, Vol. 48 No. 10, pp. 2029-2047.

MacDonald, R. and Taylor, M.P. (1993), "Regional house prices in Britain: long-run relationships and short-run dynamics”, Scottish Journal of Political Economy, Vol. 40 No. 1, pp. 43-55.

Meen, G. (1999), "Regional house prices and the ripple effect: a new interpretation", Housing Studies, Vol. 14 No. 6, pp. 733-753.

Nanda, A. and Yeh, J.H. (2014), "Spatio-temporal diffusion of residential land prices across Taipei regions", SpringerPlus, Vol. 3 No. 1.

Narayan, P.K. (2005), "The saving and investment nexus for China: evidence from cointegration tests", Applied Economics, Vol. 37 No. 17, pp. 1979-1990.

Payne, J.E. (2012), “The long-run relationship among regional housing prices: an empirical analysis of the US”, Journal of Regional Analysis \& Policy, Vol. 42 No. 1, pp. 28-35.

Pesaran, M.H., Shin, Y. and Smith, R.J. (2001), "Bounds testing approaches to the analysis of level relationships", Journal of Applied Econometrics, Vol. 16 No. 3, pp. 289-326. 
Pollakowski, H.O. and Ray, T.S. (1997), "Housing price diffusion patterns at different aggregation levels: an examination of housing market efficiency", Journal of Housing Research, Vol. 8 No. 1, pp. 107-124.

Shiller, R.J. (1990), "Speculative prices and popular models", The Journal of Economic Perspectives, Vol. 4 No. 2, pp. 55-65.

Shumway, R.H. and Stoffer, D.S. (2010), Time Series Analysis and Its Applications: With R Examples, Springer Science \& Business Media.

Teye, A.L. and Ahelegbey, D.F. (2017), "Detecting spatial and temporal house price diffusion in the Netherlands: a Bayesian network approach", Regional Science and Urban Economics, Vol. 65 No. 4, pp. 56-64.

Toda, H.Y. and Yamamoto, T. (1995), "Statistical inference in vector autoregressions with possibly integrated processes", Journal of Econometrics, Vol. 66 Nos 1/2, pp. 225-250.

Toussaint, J. and Elsinga, M. (2007), "The Netherlands: positive prospects and equity galore", in Elsinga, M., De Decker, P., Teller, N. and Toussaint, J. (eds), Home Ownership beyond Asset and Security: Perceptions of Housing Related Security and Insecurity in Eight European Counties, Housing and Urban Policy Studies, Vol. 32, pp. 287-313.

Van Dijk, B., Franses, P.H., Paap, R. and Van Dijk, D. (2011), "Modelling regional house prices”, Applied Economics, Vol. 43 No. 17, pp. 2097-2110.

Vansteenkiste, I. and Hiebert, P. (2011), "Do house price developments spill over across euro area countries?", Evidence from a Global VAR. Journal of Housing Economics, Vol. 20 No. 4, pp. 299-314.

\section{Corresponding author}

Alfred Larm Teye can be contacted at: a.l.teye@tudelft.nl

For instructions on how to order reprints of this article, please visit our website: 